\title{
ARECEPÇÃO DEADÍLIALOPESNOBRASIL
}

\author{
THE RECEPTION OF ADILIA LOPES IN BRAZIL
}

Karine Ferreira Maciel ${ }^{1}$

\section{RESUMO}

Este trabalho busca apresentar a recepção inicial que é dedicada a Adília Lopes no Brasil pela crítica editorial. O principal objetivo é apresentar quais editoras, revistas e críticos proporcionaram esse acolhimento da poetisa, comentando brevemente as causas da notoriedade da autora. Para tanto, mostraremos as organizações de antologias portuguesas pós-Pessoa editadas no Brasil e compactuaremos da teoria da estética da recepção de Hans Robert Jauss.

PALAVRAS-CHAVE: Adília Lopes; recepção brasileira; poesia contemporânea.

\section{ABSTRACT}

This paper presents the initial reception given to Adilia Lopes in Brazil by editorial critics. The main purpose is to present wich publishers, poetry magazines and critics provided this warm welcome of poetess, commenting shortly the reasons of the author's notoriety. Thus, will show the portuguese anthology organizations post Fernando Pessoa edited in Brazil and will share the theory aesthetics of reception of Hans Robert Jauss.

KEYWORDS: Adília Lopes; brazilian reception; contemporary poetry. 


a poeta portuguesa adília lopes
foi publicada em livro no brasil em 2002
desde então alguns escritores no
brasil
dialogam com a adília lopes
citam a adília lopes
incorporam versos tom humor
da adília lopes
produzindo furos na própria escrita
por onde podemos ouvir a
adília lopes

(Marília Garcia, Blind light)

A partir do início dos anos 2000, Adília Lopes ocupa um lugar de destaque na cena poética contemporânea no Brasil, seja a partir da Antologia publicada em 2002 pela editora paulista Cosac \& Naify e pela carioca 7Letras, que constava de um posfácio de Flora Süssekind, seja pela atenção que recebe na edição da revista Inimigo Rumor n ${ }^{\circ} 10$, de 2001, que lhe dedica nada menos que a publicação integral do livro O poeta de Pondichéry (1986), uma entrevista e dois ensaios críticos: um de Osvaldo Manuel Silvestre e outro de Américo António Lindeza Diogo.

Além da coleção Ás de Colete, da qual faz parte a Antologia de Adília, e junto a tantos autores que publicam pela 7Letras e travam diálogo com essa poetisa, a editora cria ainda a Coleção Guizos em 2004. A descrição da coleção, que conta com o desenho de um felino como logomarca, cita a "Autobiografia sumária de Adília Lopes 3", do livro de poemas em prosa Irmã barata, irmã batata (2000):

Os meus gatos já deixaram há muito tempo de brincar com as minhas baratas. A Ofélia tem 12 anos, seis meses e sete dias. O Guizos, segundo o Dr. Morais, tem 9 anos. Entretanto gatos morreram, gatos desapareceram. Estou a escrever isto no computador e não sei do Guizos há três dias. (LOPES, 2014, p. 418)

$\mathrm{Na}$ entrevista realizada pela revista Inimigo Rumor $\mathrm{n}^{\circ} 10$, por intermédio de Américo António Lindeza Diogo e Osvaldo Manuel Silvestre, que são alguns dos autores portugueses que alavancam a crítica positiva em torno de Adília, se declara nos parágrafos iniciais:

É talvez cedo para se saber quais os nomes que, do actual panorama poético português ganharão um dia direito a um parágrafo, ou tão-só a uma frase, nas páginas provavelmente não muito longas, dedicadas ao último quartel do século nas Histórias da Literatura Portuguesa. Que Adília Lopes venha a integrar um desses parágrafos, eis uma aposta que um número crescente de leitores vem fazendo, para irritação, enfado ou desespero dos Grandes Leitores da poesia portuguesa contemporânea. (DIOGO; SILVESTRE, 2001, p. 19) 
Já nessa introdução, percebemos uma espécie de antagonismo entre um crescente público leitor de Adília Lopes e a crítica especializada dos que Américo António Lindeza Diogo e Osvaldo Manuel Silvestre chamam os "Grandes Leitores da poesia portuguesa contemporânea", habituados, provavelmente, a uma poesia conceitual e metalinguística, como seria, por exemplo, a de Poesia 61. No texto "Adília Lopes espanca Florbela Espanca", também publicado em Inimigo Rumor no 10 , Osvaldo Manuel Silvestre diz que a crítica de Adília, considerando o cenário português, sobretudo na época de sua estreia poética, costumava se manifestar pelo silêncio e por um desmerecimento da obra da autora:

É curioso, contudo, como os críticos de Adília (que geralmente se manifestam pelo silêncio) tanto a distinguem da poesia "decente" dos nossos dias, numa altura em que quase toda a nossa poesia, de tão decentemente sentida e feita, nada é senão um breviário de boas maneiras do (e em) verso. (SILVESTRE, 2001, p. 26)

Ainda que referida a outro contexto, mais de um século depois, é interessante lembrar a afirmação de Erich Auerbach a respeito da recepção do público ao artista na década de setenta do século XIX: “[...] o pior dos perigos que ameaçavam uma obra de arte era a indiferença" (AUERBACH, 2015, p. 449).

Esse silêncio da crítica em torno da obra adiliana no contexto português - e é dessa recepção que nos fala Osvaldo Manuel Silvestre estava, provavelmente, relacionado ao tom infantil de alguns de seus poemas, à fluência e a uma certa simplicidade da sua poesia: "[...] assim como na Arte Pobre a areia é areia, a água é água e o chão uma série de tacos de madeira, em Adília a poesia é gramática, a língua é dicionário e um livro uma justaposição de textos [...]”. (SILVESTRE, 2001, p. 27). Embora, por outro lado, Osvaldo Manuel Silvestre também destaque a contradição que existe nesse público que rechaça a poesia kitsch adiliana, mas que é capaz de aceitar outras obras de cultura pop, tais quais os objetos cotidianos descontextualizados que dão autonomia ao receptor ou aquelas associadas à publicidade e à cultura capitalista globalizada:

[...] o mesmo cidadão informado e esclarecido que aprecia visitar em museus as latas de sopas de Warhol ou as mesas, os fatos de feltro e as vitrines de lixo de Beuys, resiste a considerar os versos de Adília poesia, por neles encontrar em excesso Warhol ou Beuys. Um tanto como o banqueiro do exemplo de Terry Eagleton que acha inevitáveis, e boas, as consequências da globalização - por exemplo, os 16000 postos de trabalho queimados pela fusão dos bancos Deutsche e Dresdner - mas não aceita poesia sem rima (SILVESTRE, 2001, p. 28)

No Brasil, a crítica de Adília Lopes não se manifesta pelo silêncio. Seja ela a crítica acadêmica ou editorial, os textos vão desde a panorâmica leitura de Flora Süssekind, dos textos comparatistas de Ida Ferreira Alves 
e Célia Pedrosa, da discussão de gênero empreendida por Ana Maria Domingues de Oliveira até textos que apresentam uma visão menos positiva em torno da obra da autora, como é o caso de Eucanaã Ferraz. O autor nos fala na resenha à Antologia de Adília Lopes, intitulada "De monstros e monstruosidades" ${ }^{2}$, sobre a trivialidade na poesia da autora. Ele afirma que a banalidade da linguagem e os traços antipoéticos - a circunstancialidade, os temas pouco elevados - da poesia da poetisa são similares àqueles que encontramos no Modernismo brasileiro e na geração marginal. E declara ainda que a poesia de Adília Lopes seria uma tentativa de abalo das convenções sociais, mas que não atingiria seu objetivo porque se restringiria à temática e a fórmulas ineficazes, não transgredindo radicalmente a linguagem:

[...] Mas penso que tudo isto se dá por demais no nível do tema ou da armação visível dos lances narrativos, limitando-se às "modalidades" (trocadilhos, repetições, paradoxos e afins) sem que haja uma descida à estrutura, à sintaxe, às formas de composição: ao coração da ideologia. Sabemos que não basta apontar, citar, denunciar, rir, para que se abalem os monstros sociais, sempre erguidos pela/na língua. [...] (FERRAZ, s/d, s/p)

Também são comuns as dissertações e teses dedicadas a Adília. Entre estas, a tese de Sofia de Sousa Silva ${ }^{3}$, inaugural no âmbito de trabalhos acadêmicos sobre a autora no Brasil, busca entender o papel da poesia e a sua relação com o tempo presente tanto na obra de Sophia de Mello Breyner Andresen, quanto na de Adília Lopes, levando em consideração as diferenças entre ambas no modo de conceber os elementos do mundo e de inseri-los na poesia:

[...] com Sophia estaríamos num mundo de substantivos concretos (um dos elogios que João Cabral de Melo Neto lhe teria feito), é certo, mas um mundo concreto que seria, por assim dizer, mais elevado. Adília, ao incorporar os objetos de consumo do cotidiano e as ações banais - como tomar o pequeno almoço, consultar um médico, assistir a filmes ou manter relações sexuais - parece deslocar e ampliar um projeto de atenção à imanência. (SILVA, 2007, p. 13)

Vale ressaltar aqui, sobretudo, a visibilidade de Adília Lopes no campo da crítica editorial. Jorge Fernandes da Silveira apresenta no texto "Luiza, o nu e os vestidos ou quem tem medo de Adília Lopes?" (2003) questões pertinentes a essa discussão sobre a recepção brasileira dedicada a Adília. O autor aborda o interesse que a autora desperta nos leitores brasileiros informados, principalmente os cariocas e paulistas, que ocupam um papel de destaque na poesia contemporânea brasileira, devido, principalmente, ao sucesso das antigas parceiras 7Letras e Cosac \& Naify. Além disso, o texto confronta a recepção editorial que é dedicada no Brasil a Adília e a que é destinada a Luiza Neto Jorge, com uma assumida preferência do autor pela segunda escritora. 
Entre as questões levantadas estão as razões pelas quais Luiza Neto Jorge não despertava um interesse das editoras brasileiras, ao passo que Adília despontava, sobretudo com a sua reunião poética da Cosac \& Naify, no cenário brasileiro de publicações. O autor afirma então que essas eleições não podem estar atreladas à poesia trágica de Luiza ou ao poema humorístico de Adília:

Não há de estar com certeza no horror ao trágico o espantoso desinteresse que editoras brasileiras têm manifestado em relação aos livros de Luiza e nem estará na nossa incontornável atração pelo riso, pelo poema piada, a razão para a anunciada publicação da poesia completa de Adília, reduzida no fim das contas ao recente florilégio. (SILVEIRA, 2003, p. 421)

Jorge Fernandes da Silveira explica a recepção brasileira de Adília Lopes menos pela semelhança entre Adília e a poesia que se faz no Brasil desde o século XX do que pelo fato de Adília aparentemente romper com uma falsa ideia de que a poesia portuguesa é extremamente formal.

Como leitor crítico, em suma, a minha certeza de que a melhor poesia portuguesa é diferente da melhor poesia brasileira é a razão da minha hipótese de interpretação da recepção de Adília entre nós como resultado da falsa convicção de que a poesia portuguesa hoje é tudo o que a dela não é: grandiloquente, convencional, formal, chata. (SILVEIRA, 2003, p. 424)

A questão levantada por Silveira toca, exatamente, em um ponto explicitado por Carlito Azevedo. O poeta organizou a já referida Antologia de Adília Lopes publicada pela Cosac \& Naify e pela 7Letras na Coleção Ás de Colete. Em entrevista ao jornal português Público, em 2009, conduzida pela jornalista Alexandra Lucas Coelho, faz uma afirmação nada técnica sobre (a poesia de) Adília Lopes: "É o amor da minha vida. É a mulher da minha vida - que nunca vi!”. Uma das poucas vezes em que diz o que admira tanto na poesia de Adília, aparece no fragmento:

Uma das coisas que mais me chamou a atenção na Adília é que, de entre os clichés que se faz de uma poesia de um país, lá no Brasil existia a ideia de que a poesia portuguesa ou seria aquela coisa da geração de 61 , mais intelectualizada, ou o lirismo derramado. Mas eu não esperava tanta ironia - e tanto amor. Era imprevisível demais. (AZEVEDO, 2009, s/p)

Tal discussão nos permite confirmar duas hipóteses. Uma que diz respeito à afirmação de Jorge Fernandes da Silveira de que a poesia portuguesa era concebida no Brasil, pelo menos até 2000 e sem levar em consideração o ambiente universitário, como algo convencional. E a outra, trazida por Carlito Azevedo, é a visão polarizada que se tinha no Brasil sobre a poesia portuguesa, uma vez que ela ou era altamente intelectualizada ou extremamente lírica. E Adília romperia assim com essa concepção que o próprio Carlito Azevedo reconhece como falsa quando se refere a "clichés que se faz de uma poesia de um país”(AZEVEDO, 2009, s/p). Por outro lado, 
a fala do poeta carioca também destaca a ironia pulsante na poesia de Adília, questão levantada por Rosa Maria Martelo no texto "Contra a crueldade, a ironia", ${ }^{4}$ no qual a ironia é desdobrada em vários níveis para se entender esta poesia. Essa questão é relevante para aproximar Adília Lopes de outro poeta “imprevisível demais”, Mário Cesariny de Vasconcelos.

\section{POR QUE NÃO CESARINY?}

Quando pensamos na poesia de Adília Lopes, dentro do cenário da poesia brasileira, não conseguimos desvinculá-la da mesma vertente cotidiana, circunstancial e permeada de humor que constitui a poesia contemporânea feita no Brasil e presente já na poesia modernista e na geração marginal. E é bem possível que a recepção positiva de Adília no Brasil se dê também por uma questão de semelhança e reconhecimento, hipótese menos aceita por Jorge Fernandes da Silveira, mas que será tomada aqui como a principal causa do acolhimento da autora no Brasil, sobretudo se pensarmos na paridade do prosaísmo da autora portuguesa e dos poetas brasileiros. Hans Robert Jauss afirma que o efeito da recepção é extremamente subjetivo e indeterminável, seja no plano individual, seja no coletivo. No entanto, existem parâmetros que podem delinear o tipo de público de cada obra:

[...] como em toda experiência real, também na experiência literária que dá a conhecer pela primeira vez uma obra até então desconhecida, há um "saber prévio, ele próprio um momento dessa experiência, com base no qual o novo de que tomamos conhecimento faz-se experienciável, ou seja, legível, por assim dizer, num contexto experiencial". Ademais, a obra que surge não se apresenta como novidade absoluta num espaço vazio, mas, por intermédio de avisos, sinais visíveis e invisíveis, traços familiares ou indicações implícitas, predispõe seu público para recebê-la de uma maneira bastante definida. Ela desperta a lembrança do já lido, enseja logo de início expectativas quanto a "meio e fim", conduz o leitor a determinada postura emocional e, com tudo isso, antecipa um horizonte geral da compreensão vinculado, ao qual se pode, então - e não antes disso - , colocar a questão acerca da subjetividade da interpretação e do gosto dos diversos leitores ou camadas de leitores. (JAUSS, 1994, p. 11)

Diante disso, podemos afirmar que a obra de Adília Lopes atende a um certo "horizonte de expectativa" (JAUSS, 1994, p. 10) dos leitores, críticos e poetas da poesia contemporânea brasileira, já que vai ao encontro de uma memória de poesia cotidiana, permeada do discurso popular — sem prescindir da tradição - e em que a distinção entre linguagem prática (não literária) e poética é ainda muito tênue. ${ }^{5}$ Dessa maneira, a autora aproxima-se da irreverência, da linguagem coloquial e da circunstancialidade presentes na poesia contemporânea brasileira de Ana Martins Marques, Alice Sant'Anna ou Angélica Freitas, que, por sua vez, são poéticas que trazem já esses traços do Modernismo brasileiro, sobretudo da geração de 1922 e 
dos instantâneos versos humorísticos de Oswald de Andrade, dos traços biográficos de Losango Cáqui do Mário de Andrade e do lirismo palatável, permeado de referências da "Balada das três mulheres do sabonete araxá", de Manuel Bandeira.

Por questões quantitativas e eletivas que demandariam uma comparação específica com cada poeta, brasileiro e contemporâneo, similar à autora, esse texto propõe-se menos a especificar as causas da recepção e muito mais a perceber esse fenômeno dentro do campo editorial, embora valendo-nos da hipótese de que o acolhimento da autora portuguesa ocorre em razão da familiaridade que a sua poética provoca nos poetas e editores brasileiros. Para um estudo posterior, estariam resguardadas as similitudes entre a poética da autora e dos poetas contemporâneos brasileiros, seja através da citação nominal da autora e de seus poemas ou de aproximações temáticas e formais. Como amostra, notemos, brevemente, em que consiste essa semelhança, a ser investigada em um texto posterior e mais esmiuçado.

O poema de Sete rios entre campos (1999): A minha cara / é uma caraça / que o tempo-traça / traça" (LOPES, 2014, p. 365) pode ser visto ao lado de um poema de Rilke Shake (2007), de Angélica Freitas:

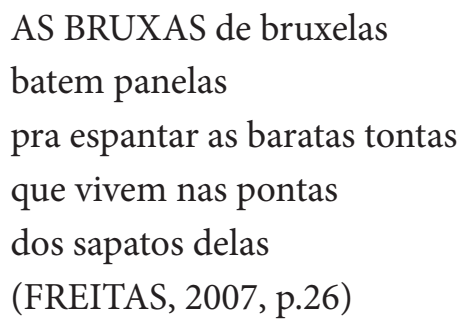

Os poemas aproximam-se tanto pela brevidade como pela maneira que trabalham a linguagem. Adília a reinventa em um jogo fonético-morfológico, através da derivação cara / caraça, da ambivalência do termo traça, ora substantivo, ora verbo. Um trabalho semelhante ao de Angélica Freitas, que além da rima fácil, emprega aliterações plosivas: bruxa / bruxelas; batem / baratas; panelas / pontas. Ambas apresentam um trabalho muito objetivo de enunciação, seja através da narração (no presente) ou da descrição.

Por outro lado, para além do prosaísmo adiliano, as afirmações de Jorge Fernandes da Silveira e de Carlito Azevedo, que são embasadas pelo mesmo argumento, nos fazem pensar em outro poeta português anterior e também extremamente irreverente: Mário Cesariny. Qual o lugar desse poeta na poesia contemporânea brasileira? Por que, mesmo rompendo com a extrema intelectualização da poesia e com o lirismo exacerbado, o poeta não ocupou um lugar semelhante ao de Adília? O surrealista português também trouxe, 35 anos antes da poetisa - o primeiro livro publicado por Cesariny, Corpo visível, data de 1950 - , a ironia e o humor para dentro de uma época que ainda vivia a literatura político-social neorrealista. 
Segundo a tese de doutorado de Maria de Fátima Aires Marinho Saraiva, intitulada O Surrealismo em Portugal e a Obra de Mário Cesariny de Vasconcelos (1986), mesmo quando inserido no início dos anos 40, Mário Cesariny nunca "se pôde considerar um autor neo-realista convicto" (SARAIVA, 1986, p. 311) e seus escritos já anunciavam não só outros valores literários, como uma crítica a essa escola. A partir do capítulo "De um Neo-Realismo Crítico e Irônico a Um Surrealismo Fora do Comum”, da tese de Maria de Fátima Marinho Saraiva, podemos perceber a irreverência na produção de Mário Cesariny.

Em uma obra de $1944^{6}$, Mário Cesariny já mostrava características da sua veia irônica. Tal obra intitula-se Nicolau Cansado escritor, e consta de um autor fictício - como notou Maria de Fátima Marinho Saraiva, recurso explorado não só na tradição portuguesa, como na literatura latina e nos romances alemães e ingleses, porém inédito no autor de Pena capital - e de uma crítica nomeada Marília Palhinha, da mesma ordem ficcional do autor. Essa obra de poesia traz um retrato pouco elogioso dos neorrealistas, como afirma Maria de Fátima Marinho Saraiva:

Pelo que deixámos dito, não será difícil de perceber o tom irónico e parodístico de que se reveste este conjunto de poemas. A ironia marca uma distanciação em relação ao neo-realismo, a consciência da sua total inoperância ao nível prático e ao nível estético. (SARAIVA, 1986, p. 314)

\section{"Vamos ver o povo \\ Que lindo é \\ Vamos ver o povo \\ Dá cá o pé"}

(VASCONCELOS in SARAIVA, 1986, p. 314)

A autora afirma ainda que "[s]ó um mestre na arte do humor como Cesariny seria capaz de tais afirmações." (SARAIVA, 1986, p. 313) Essa assertiva diz respeito ao poema "Fantasia Gramática e Fuga (com Eco)", que faz uma crítica aos neorrealistas, burgueses que julgavam os ideais dessa classe, mas eram incapazes (ou fingiam ser) de se enxergarem como parte dela, segundo a concepção de Cesariny: "No fundo eu não sinto / como sou burguês / minto minto minto / vês? vês? vês?" (VASCONCELOS in SARAIVA, 1986, p. 314). Essa crítica será ainda muito insistente, abrangendo poemas como "Raio de Luz" ou o estudo crítico de Marília Palhinha.

O humor aparece também no livro Discurso sobre a reabilitação do real quotidiano (1952), já mais permeado do "nonsense, tão do agrado da estética bretoniana" (SARAIVA, 1986, p. 346), que a autora da tese ilustra com o poema:

no país no país no país onde os homens

são só até ao joelho

e o joelho que bom é só até à ilharga

conto os meus dias tangerinas brancas 
e vejo a noite Cadillac obsceno

a rondar os meus dias tangerinas brancas

para um passeio na estrada Cadillac obsceno

(VASCONCELOS in SARAIVA, 1986, p. 346)

Também em Louvor e simplificação de Álvaro de Campos (1953), livro que homenageia e parodia o heterônimo Álvaro de Campos, e em Nobilíssima visão (1956), o humor se faz presente. Deste último a autora destaca os poemas "Todos por um", que ironiza não mais os neorrealistas, mas os poetas românticos, e "Pastelaria", o qual "canta a importância fundamental do riso" (SARAIVA, 1986, p. 320).

Ainda sobre Nobilíssima visão, o trabalho de Maria de Fátima Marinho Saraiva confirma o humor de Cesariny e, a respeito de um comentário de João Palma Ferreira que diz que tal obra é a "menos surrealista que até agora [Cesariny] escreveu" (FERREIRA in SARAIVA, 1986, p. 316), afirma:

Completando as afirmações de João Palma Ferreira, convém salientar que se, na verdade, Nobilíssima Visão não possui elementos surrealistas de grande monta, não é menos verdade que ela constitui uma visão humorística do mundo (por vezes bem à maneira surrealista), onde surgem ingredientes neo-realistas para serem imediatamente ultrapassados. (SARAIVA, 1986 p. 316)

Como contraponto da desconstrução pelo viés irônico e humorístico do surrealista português, traremos algumas questões acerca desse tópico em Adília Lopes. Rosa Maria Martelo, no já referido texto "Contra a crueldade, a ironia", defende que Adília Lopes é uma ironista, pois reinventa uma linguagem a fim de distanciar-se do senso comum: “[...] para a ironista, o senso comum é, antes de mais, uma linguagem que só pode ser objeto de distanciação mediante outra linguagem" (MARTELO, 2010, p. 224). Podemos notar essa reinvenção da linguagem em um poema de Le vitrail la nuit ${ }^{*}$ A árvore cortada, que dialoga com o quadro Almoço na Relva, de Édouard Manet:

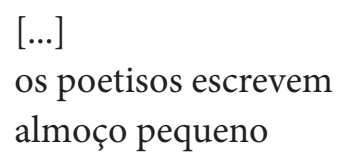

$[\ldots]$

os poetisos escrevem

almoço pequeno

Sobre a erva

sobre a relva

(LOPES, 2014, p. 589)

O poema traz um equivalente perfeito, no nível do radical morfológico, para a flexão de gênero: poetiso / poetisa. Mas a derivação empreendida por Adília - "poetiso" - já rompe com um princípio de formação de palavras da língua portuguesa, na qual as formações femininas são secundárias e semanticamente relacionadas às formas masculinas. De maneira que "poetisa" é uma palavra feminina, com o sufixo derivacional -isa, que advém da forma masculina "poeta". No entanto, o que ela propõe é uma 
inversão, já que o equivalente masculino passa a ser formado a partir do vocábulo feminino "poetisa".

A poetisa portuguesa é também ironista quando sua "poesia apresenta-se como uma possibilidade de repensar (entenda-se de refazer) o seu vocabulário final." (MARTELO, 2010, p. 224) Assim ocorre em "Os poemas que escrevo", de Um jogo bastante perigoso, já citado por Rosa Maria Martelo, sobre o qual ela afirma:

Uma das estratégias de escrita mais características de Adília Lopes passa precisamente pelo questionamento de saberes discursivamente consignados, através de uma redistribuição dos elementos lexicais que os veiculam. É o princípio, já referido, das "[...] águas que moem / os moinhos / que andam ao contrário"; no caso, a funcionar através da reelaboração afirmativa do ditado "águas passadas não movem moinhos" (MARTELO, 2010, p. 229)

Uma das vias da ironia de Adília é justamente uma maneira de contornar o sofrimento e a humilhação, tal qual o poema sobre a personagem da Dr. a Manuela Brazette, de Irmã Barata, Irmã Batata:

Em 81, disse à Dr. ${ }^{\text {a }}$ Manuela Brazette, psiquiatra, "Eu sou feia". Ela disse-me "Não é ser feia. Não há pessoas feias. Não tem é atractivos sexuais". Lembrei-me então do homem que em 74, tinha eu 14 anos, se cruzou comigo no Arco do Cego. Lembrei-me do homem, da cara do homem vagamente, mas lembrei-me muito bem do que ele me tinha dito ao passar por mim. Tinha-me dito 'Lambia-te esse peitinho todo'. Lembrei-me também da meia dúzia de outros homens que durante a minha adolescência me tinha dito quando eu passava 'Coisinha boa' e 'Borrachinho'. Ainda hoje me sinto profundamente agradecida a esses homens. Pensei que eles estavam a avacalhar, que eram uns porcalhões. Mas quem estava a avacalhar era a Dr. ${ }^{a}$ Manuela Brazette, ela é que é uma porcalhona. Acho que um homem nunca consegue ser mau para uma mulher como outra mulher. (LOPES, 2014, p. 408)

Como consolação, o "humor é, naturalmente, um aliado precioso." (MARTELO, 2010, p. 224). Sobre esse recurso paralelo à ironia, Álvaro Luiz Montenegro Valls afirma: "Poderíamos dizer que rir não deixa de ser, além de uma forma de ataque, também uma forma de defesa, de defesa da sua própria subjetividade [...]" (VALLS, 2000, p. 21).

É dessa maneira que encaramos os textos de Adília Lopes, que apresentam a autoironia como uma forma de proteção contra os discursos cruéis que pregam em prol de padrões de beleza ou de instâncias que consagram a inteligência como fator de superioridade. O poema sobre a personagem da Dra Manuela Brazette aparece ao lado de "Body art?" como mostra de uma ironia mais rara, de que nos fala Kierkegaard citado por Valls, na qual a brincadeira de tom sério cede lugar ao sério em tom de brincadeira: "A forma mais corrente de ironia consiste em dizermos num tom sério o que, 
contudo, não é pensado seriamente. A outra forma, em que a gente brincando diz em tom de brincadeira algo que se pensa a sério, ocorre raramente." (KIERKEGAARD apud VALLS, 2000, p. 25)

Após esta breve comparação, retornemos à questão da recepção. No primeiro momento em que Cesariny é publicado em Portugal, no contexto literário brasileiro vivia-se, no romance, um engajamento social de tom regionalista; na poesia, o equilíbrio e a objetividade de João Cabral de Melo Neto e o prenúncio da poesia concreta, que despontaria a partir de 1956. E, embora o poeta-engenheiro estivesse também atrelado a tendências surrealistas - pelo menos no seu livro de estreia Pedra do sono (1942) -, não havia nele, e não houve em nenhum artista brasileiro, uma vinculação ao Surrealismo como um movimento literário propriamente dito, como houve em Portugal, e o que se nota em Cabral é, sobretudo, um resquício da pintura surrealista e da sua sobreposição de imagens insólitas, como notamos em versos como: "A bailarina feita / de borracha e pássaro" (CABRAL, 1985, p. 18).

A objetividade da poesia de Cabral, pouco dada à pessoalidade, à circunstancialidade e ao coloquialismo, e o formalismo da geração de 1945 justificariam, em parte, um silêncio em torno de Mário Cesariny no Brasil, ao menos no que diz respeito aos poetas. E se houve uma possibilidade de recepção portuguesa nos anos 40 por parte de Cabral, não há dúvida de que a sua maneira de aliar valores éticos e estéticos contribuía para que fosse Sophia de Mello Breyner Andresen a voz poética escolhida. Em A educação pela pedra, o autor inclui um poema intitulado "Elogio da usina e de Sophia de Mello Breyner Andresen”.

É evidente que, associado ao contexto literário da época e a partir de diferenças significativas entre Cesariny e os poetas brasileiros que lhe eram contemporâneos, os moldes de publicação, divulgação e integração nos anos 40 eram incomparavelmente mais restritos do que os atuais, que contam com o avanço da tecnologia e de todas as suas ferramentas. Isso explica também por que, a partir dos anos 2000, os poetas portugueses, como Adília Lopes e Ruy Belo, terão destaque no Brasil. A revista brasileira Inimigo Rumor estabeleceu parceria com Portugal da edição número 11 até a número 16, incluindo muitos textos de poetas e críticos portugueses, como, por exemplo, a revista número 15, que trazia um dossiê sobre o Ruy Belo. A já citada revista número 10 parece ter anunciado esse projeto de aproximação.

No âmbito editorial brasileiro, mesmo anterior aos anos 2000, Mário Cesariny apresenta uma significativa aparição, uma vez que o autor de Pena capital se faz notar em todas as antologias brasileiras de poesia portuguesa contemporânea, - como veremos adiante - com exceção da de Cecília Meireles, por essa datar de 1944, antes da primeira publicação de Cesariny.

Dessa forma, podemos concluir que a recepção de Cesariny, por parte da crítica editorial antes dos anos 2000, existiu. E que se não houve uma recepção a nível daquela que é dedicada a Adília Lopes, foi devido a 
uma pouca identificação dos poetas brasileiros da época, somada à menor integração entre os países por questões de avanços tecnológicos. Temos, portanto, que Adília Lopes desponta no cenário brasileiro como uma autora de sucesso, porque os seus poetas contemporâneos brasileiros, ao perceberem na sua poética características similares, lhe dão muita importância, o que parece ter faltado não só a Cesariny — ressaltado aqui por ser, entre todos os outros portugueses, um poeta que apresenta uma obra dotada de ironia $\mathrm{e}$ humor que o situa em um lugar marginal em relação ao cânone português, ao mesmo tempo que o aproxima de Adília Lopes - , como a todos os outros autores de poesia pós-Fernando Pessoa.

\section{A POESIA PORTUGUESA PÓS-PESSOA NO BRASIL}

Sem dúvida, Fernando Pessoa é o representante mais notório da moderna poesia portuguesa - e não só no Brasil - sendo, inclusive, em uma afirmação que inicialmente pode parecer contraditória, dispensado na imaginária antologia brasileira de poesia portuguesa de Jorge Fernandes da Silveira. Isso, claro, aliado ao critério de seleção do organizador, que pretendia apresentar ao leitor brasileiro "poetas pouco ou nada conhecidos":

Ele está em todas as bancas (de acadêmicos, livreiros e jornaleiros) como está em todos os bancos (comerciais, públicos e escolares). Logo, primeira conclusão grosseira: não precisa fazer número numa seleção cujo principal objetivo é apresentar ao brasileiro leitor de poesia poetas que lhe sejam pouco ou nada conhecidos, desde o aparecimento do presencismo. [...] (SILVEIRA, 2003, p. 179-180)

Levando em conta as mais recentes antologias brasileiras de poesia portuguesa, é interessante trazer para essa discussão a Antologia da poesia portuguesa contemporânea: um panorama, organizada por Alberto da Costa e Silva e Alexei Bueno, que vem a lume em 1999. Essa organização por dois antologistas de gerações diferentes norteia-se pela "[...] grande abrangência, buscando recensear todas as muito variadas correntes da poesia portuguesa da segunda metade deste século [...]" (SILVA; BUENO, 1999, p. 21). E justamente essa tentativa panorâmica - presente, inclusive, no título - é um critério oposto ao que é estabelecido por Jorge Fernandes da Silveira para sua antologia:

[...] Mais importante é afastar do projeto a id[e]ia de panorama (de poesia ou de poéticas) e deixar claro que é um hábito de ler, desenvolvido a partir do convívio com os poetas mais amados e do nível de exigência e expectativa que a leitura desses mesmos poetas implica, [...] que faz com que essa antologia se apresente como uma conversação entre alguns poetas portugueses do século XX sob a supervisão de um leitor brasileiro informado e interessado. (SILVEIRA, 2003, p. 178) 
Dessa forma, considerada a conversação entre os poetas selecionados pelo organizador, Fernando Pessoa, embora não apareça diretamente como um autor eleito, apareceria dentro do discurso de outros, tais como Ruy Belo, Fiama Hasse Pais Brandão e Sophia de Mello Breyner Andresen.

Por outro lado, é interessante ressaltar que a antologia de Jorge Fernandes da Silveira abrangeria, em uma relação contextual com a história de Portugal, o período de 1920 a 1970, enquanto a antologia de Alberto da Costa e Silva e Alexei Bueno tem como marco cronológico a segunda metade do século XX, uma vez que a sua abertura parte da antologia Poetas novos de Portugal, organizada por Cecília Meireles em 1944. No entanto, o aspecto relevante é que Silveira elege 40 nomes para sua antologia, dos quais 31 também aparecem na antologia - bem mais ampla, constando de 72 autores - de Silva e Bueno.

Esta discussão não está restrita a uma comparação de critérios eletivos entre as antologias, e se isso ocorre é por entendermos que há uma necessidade de especificar que mesmo as antologias com perspectivas opostas apresentam uma grande semelhança na sua seleção de autores. A fim de identificarmos os autores constantes nas organizações antológicas, trazemos à baila outras duas antologias imediatamente anteriores a de Jorge Fernandes da Silveira e de Alberto da Costa e Silva e Alexei Bueno. A primeira, de 1967, foi organizada por João Alves das Neves e intitula-se Poetas portugueses modernos, e a segunda, organizada em 1982 por Carlos Nejar, apresenta um título (quase) homônimo ao de Silva e Bueno: Antologia da poesia portuguesa contemporânea. Citamos, portanto, os poetas que são constantes nas quatro antologias: António Gedeão, Sophia de Mello Breyner Andresen, Jorge de Sena, Raul de Carvalho, Carlos de Oliveira, Eugénio de Andrade, Mário Cesariny, Alexandre O’Neill, António Ramos Rosa, David Mourão Ferreira e Herberto Helder. Se incluirmos ainda a antologia organizada por Alfredo Margarido e C. E. Costa, intitulada Doze jovens poetas portugueses e publicada em 1953, posterior apenas à antologia de Cecília Meireles, notaremos que os dois poetas comuns a todas essas antologias são Eugênio de Andrade e Mário Cesariny.

Considerando que Adília Lopes surge no cenário poético apenas em 1985, só seria possível a sua inclusão nas duas antologias mais recentes. No entanto, como o critério cronológico de Jorge Fernandes da Silveira não contempla as produções poéticas após 1970, é perfeitamente justificável a ausência da autora.

No que diz respeito à antologia de Alberto da Costa e Silva e Alexei Bueno, os organizadores elegem três poemas de Adília Lopes, de livros diferentes: "Para um vil criminoso", do seu primeiro livro, Um jogo bastante perigoso (1985); "Autobiografia sumária de Adília Lopes", do seu terceiro livro, A pão e água de colónia (1987); e, por último, o poema "A ladainha minha", do seu sexto livro, Os 5 livros de versos salvaram o tio (1991). 
Após essa discussão, foi possível notar a relevância, sobretudo a partir dos numerosos textos que abordam a poetisa portuguesa, que Adília Lopes ocupa no circuito editorial brasileiro, sobretudo entre as capitais Rio de Janeiro e São Paulo. O sucesso da poetisa no Brasil, incomparável ao de qualquer outro autor ou autora portugueses de poesia pós-Fernando Pessoa, embora associado às semelhanças da poética da autora - coloquialismo, banalidade, poema-piada - com a poesia contemporânea brasileira, ganhariam destaque em um número posterior, no qual se pudesse, além de descrever essa recepção editorial, mostrar também a recepção da autora pelos poetas, aprofundando assim os traços que fazem de Adília Lopes uma autora familiar e que contribuem para a sua boa acolhida.

Esse questionamento foi importante para pensar por que o poeta Mário Cesariny, também cultor do humor e da ironia, não alcançou, antes dos anos 2000, o sucesso de Adília Lopes. Sustentamos que tal fato não se deu devido a pouca equiparação entre as características de Cesariny e aquelas apresentadas, na poesia, por seus contemporâneos brasileiros de 1945. Aliado a isso, incluímos a facilidade de divulgação e integração, proporcionada pelos avanços tecnológicos, entre as produções poéticas que são feitas atualmente e que não ocorriam com tanta rapidez nos anos 40. Por outro lado, percebemos que no campo editorial, a partir das antologias brasileiras de poesia portuguesa contemporânea, Mário Cesariny mostrou-se como um autor importante, aparecendo em absolutamente todas as antologias brasileiras que são posteriores ao seu surgimento em Portugal.

Encaradas em conjunto, temos que a familiaridade da obra de Adília Lopes no imaginário da poesia brasileira, e a globalização, que permite maior difusão e integração entre os países, mostraram as possíveis razões da boa recepção da obra poética de Adília Lopes no Brasil.

\section{REFERÊNCIAS BIBLIOGRÁFICAS}

AUERBACH, Erich. Germinie Lacerteux. In: Mimesis: a representação da realidade na literatura ocidental. Perpectiva: São Paulo, 2015, p. 443-470.

AZEVEDO, Carlito. Entrevista com Carlito Azevedo. Público. Lisboa: 2009. Disponível em: <https://www.publico.pt/culturaipsilon/noticia/para-entender-o-mundo-vou-ler-os-poetas-novos-227253> Último acesso em: 22 abr. 2016.

DIOGO, Américo António Lindeza; SILVESTRE, Osvaldo Manuel. Entrevista com Adília Lopes. In: Inimigo Rumor. Rio de Janeiro: 7Letras, n.10, p.19-23, 2001.

FERRAZ, Eucanaã de Nazareno. De monstros e monstruosidades. Blog de Eucanaã Ferraz. Disponível em: <http://www.eucanaaferraz.com. br/sec_textos.php> Acesso em: 25 jun 2017. 
JAUSS, Hans Robert. A história da literatura como provocação à teoria literária. Trad. Sérgio Tellaroli. São Paulo: Ática, 1994. Disponível em: https://ufprbrasileiraluis.files.wordpress.com/2015/02/jauss-arquivo-melhor.pdf $>$ Acesso em: 20 jun. 2017.

LOPES, Adília. Dobra - Poesia reunida 1983-2014. Lisboa: Assírio \& Alvim, 2014.

Antologia. São Paulo / Rio de Janeiro: Cosac Naify / 7 Letras, 2002.

MARTELO, Rosa Maria. Contra a crueldade, a ironia. In: A forma informe - leituras de poesia. Lisboa: Assírio \& Alvim, 2010, p. 223-234.

SARAIVA, Maria de Fátima Aires Pereira Marinho. O Surrealismo em Portugal e a Obra de Mário Cesariny de Vasconcelos. 740 p. Tese (Doutorado em Letras) - Faculdade de Letras, Universidade do Porto. Porto, 1986.

SILVA, Alberto da Costa; BUENO, Alexei. Antologia da poesia portuguesa contemporânea: um panorama. Seleção e introdução Alberto da Costa e Silva e Alexei Bueno. Rio de Janeiro: Lacerda Ed., 1999.

SILVA, Sofia Maria de Sousa. Reparar brechas: a relação entre as artes poéticas de Sophia de Mello Breyner Andresen e Adília Lopes e a tradição moderna. 118 p. Tese (Doutorado em Letras) - Pontifícia Universidade Católica do Rio de Janeiro, Rio de Janeiro, 2007.

SILVEIRA, Jorge Fernandes da. Luiza, o nu e os vestidos ou quem tem medo de Adília Lopes. In: Verso com verso. Coimbra, Angelus Novus, 2003, p. 417-424.

. "Neste momento a minha mão não tem autor": introdução ao primeiro volume de uma imaginária antologia brasileira da poesia portuguesa no século XX - 1920-1970. In: Verso com verso. Coimbra: Angelus Novus, 2003, p. 177-191.

SILVESTRE, Osvaldo Manuel. Adília Lopes espanca Florbela Espanca. Inimigo Rumor (número 10). Rio de Janeiro: 7Letras, 2001, p.24-28.

VALLS, Alvaro Luiz Montenegro. Observações sobre o conceito da ironia em Sócrates,

Hegel e Kierkegaard. In: Entre Sócrates e Cristo: ensaios sobre a ironia e o amor em Kierkegaard. Porto Alegre: EDIPUCRS, 2000, p. 19-34.

Recebido para avaliação em 14/01/20 Aprovado para publicação em 24/02/19

\section{NOTAS}

1 Doutoranda no Programa de Pós-Graduação em Literatura Comparada da Universidade Federal Fluminense. 
2 Disponível em: <http://www.eucanaaferraz.com.br/sec_textos.php> Acesso em: 25 jun 2017. O texto encontra-se no blog de Eucanaã Ferraz. Não foi possível identificar exatamente a data da sua publicação.

3 Reparar brechas: a relação entre as artes poéticas de Sophia de Mello Breyner Andresen e Adília Lopes e a tradição moderna (2007)

4 In: A forma informe: leituras de poesia (2010).

5 Cabe ressaltar, que esses conceitos de diferenciação dessas linguagens (a prática e a poética) advêm da história literária formalista, e dizem respeito ao fato de a linguagem poética romper com a percepção automatizada do cotidiano, através do requinte estético, ao passo que a linguagem prática não atinge o status de linguagem literária, não causa um certo "estranhamento". Sobre a diferenciação desses conceitos, nos esclarece Hans Robert Jauss em A história da literatura como provocação à teoria literária: "[...] A diferenciação entre linguagem poética e linguagem prática conduziu ao conceito de percepção artística, conceito este que rompe completamente o vínculo entre literatura e vida. A arte torna-se, pois, o meio para a destruição, pelo "estranhamento", do automatismo da percepção cotidiana. [...]" (JAUSS, 1994, p. 7). Muito embora a linguagem coloquial, associada nesses conceitos da literatura formalista à linguagem prática, provoque também um "estranhamento", o que tornaria, assim, o coloquialismo um elemento que romperia com essas duas categorias aparentemente dicotômicas, uma vez que pertence a esses dois polos da linguagem.

6 Sobre o fato dessa obra ser anterior ao primeiro livro publicado de Cesariny, nos esclarece Maria de Fátima Marinho Saraiva: “[...] Apesar de o seu [de Mário Cesariny] primeiro livro datar de 1950, Cesariny começara a escrever, que se saiba, cerca de dez anos antes e, curiosamente, não são esses primeiros escritos que vêm então a público [...]” (SARAIVA, 1986, p. 305) 